\title{
O Sol laranja E NEgro de JoÃo Cabral de MElo Neto
}

Luciana Tiscoski

Doutoranda em Teoria Literária - PPGL/UFSC

lutis@,terra.com.br

O poeta pernambucano João Cabral de Melo Neto publica Sevilha andando em 1990, já aposentado da carreira diplomática que lhe possibilitou o contato com a cidade e o povo sevilhano, desde 1956, quando trabalha em pesquisas históricas no Arquivo das Índias de Sevilha. Após ter morado em cidades como Londres, Marselha e Barcelona, é transferido para a andaluza Cadiz, e novamente reside em Sevilha em 1962. Tendo ainda passado no decorrer de sua carreira diplomática por Berna, Senegal e Honduras, é a Andaluzia que se estabelece como lugar da linguagem poética e concreta, eleita Sevilha a cidade onde os elementos de sua poesia se realizam em lâmina, pedra, o sol laranja e negro, a mulher que anda. Sevilha andando e Andando Sevilha finalizam sua produção poética e reproduzem em serena e bruta semelhança o homem da terra que lhe remete ao sertanejo, a Pernambuco, a Recife. Do Capibaribe ao Guadalquivir, a terra é banhada e seca, por um mesmo rio e um mesmo sol árido de concretude ácida, cortante. Ambos os rios deságuam no Oceano Atlântico, essa imensidão de fora, insondável e inatingível em sua totalidade, como Pernambuco e a Espanha, porque o poeta, segundo Blanchot (2011, p. 85), "é aquele para quem não existe sequer um único mundo, porque para ele só existe o lado de fora, o fluxo do eterno exterior". Essa experiência do fora na linguagem de Cabral é aquela que coloca a poesia em relação direta com o mundo da imagem e do objeto, do abstrato ao concreto, sem os enleios de um pensamento que se traduz em transcendência metafísica, uma metafísica "que trata dos erros fundamentais do homem, como se fossem verdades fundamentais", conforme Nietzsche (2005, p. 28).

A experiência desse fora nas imagens de Pernambuco e Sevilha não se esquivava de "ganhar a alma do espectador" com "elementos de inquietação" comedida e também traz "alguma desordem que tateia às cegas, de sonho atento, como artifícios engenhosos para dispor a alma do espectador ou ouvinte de forma que ela creia no brotar repentino do perfeito" (Nietzsche, 2005, p. 107). No entanto, em Cabral, os artifícios engenhosos existem na medida justa de imagens que se ordenam diante da desordem da cegueira. Tratase de uma cegueira clara, convicta, sem neblinas, um sonhar de olhos abertos. É uma engenhosidade não no sentido de reunir qualidades inatas (ingenium ou ingeniosus), mas no sentido que Nietzsche designava como o gênio, aquele que "aprende antes a assentar 
pedras e depois construir, sempre buscando matéria-prima e sempre a trabalhando" (2005, p. 115).

O lugar onde se encontram a Espanha e Pernambuco é o lugar onde se constrói sua linguagem na apreensão de uma matéria-prima que nasce da pedra, lapidada pela "aritmética do metal". A desordem dá lugar a uma arquitetura exata, matemática. As imagens da paisagem urbana e natural da cidade de Sevilha, plana, árida e clara, o jeito de ser da gente sevilhana, ou castelhana, como prefere Luís Costa Lima, estão em Pernambuco como em sua poesia. Segundo o crítico, além das referências geográficas das paisagens castelhana e nordestina, com sua "desnudez árida", "elas se identificam pelo homem que geram, seco, sem hálito de chuva, antes perseguido pela História que dela perseguidor" (Lima, 1966, p. 337). Não há nessas cidades, como nos poemas criados a partir delas por Cabral, a exuberância de florestas, cores, nuvens e demais motivos oníricos, há rios como cachorros, mulheres de tornozelos grossos que se enraízam na terra, pedras esculpidas e lapidadas até o osso.

Os lugares se fundem num só fora, numa mesma arquitetura de linguagem que se revela em Sevilha, reflexiva, especular, plana como a superfície do espelho. Sevilha é o "habitar-se", o "ir-se e vir-se". Cabral transfere a "sevilhização do mundo" à sevilhização de sua linguagem. E cumpre lembrar que, na elaboração de uma experiência "do fora", o poeta escreve sobre Pernambuco quando estava na Espanha e escreve sobre a Sevilha estando no Brasil.

Anda Sevilha dando-se a ver, dentro da linguagem poética cabralina. É o que se encontra em quase confissão logo nas três primeiras estrofes do poema que abre Sevilha andando.

$$
\begin{aligned}
& \text { Quando queria dá-la a ver } \\
& \text { ou queria dá-la a se ver, } \\
& \text { ei-lo então incapaz de todo: } \\
& \text { nada sabe dizer de novo. } \\
& \text { Só reencontra as coisas ditas } \\
& \text { e que ainda diz de Sevilha. }{ }^{1}
\end{aligned}
$$

A concisão da escrita cabralina foi se construindo desde, ou apesar de, sua passagem pelo surrealismo francês. De Stéphane Mallarmé (1842-1898) incorpora o "ser da linguagem"2, onde se dá a "desaparição elocutória do poeta" e a "respiração perceptível no

${ }^{1}$ MELO NETO, João Cabral de. "A sevilhana que não se sabia". In: Sevilha andando. Obra completa/João Cabral de Melo Neto. Rio de Janeiro: Nova Aguilar, 1994, p. 629.

2 “[...] Roland Barthes afirma que para Mallarmé "é a linguagem que fala, não o autor; escrever é, através de uma impessoalidade prévia (...), atingir esse ponto onde só a linguagem age, 'performa', e não 'eu’: toda a 
antigo sopro lírico" cede espaço à iluminação recíproca das palavras, "como um virtual rastro de fogos sobre pedrarias"3. Mas desde sempre, podem-se vislumbrar possíveis afinidades com Paul Valéry (1871-1945), como “a coragem de viver em frente à imagem” e a capacidade de retirar dos "tortuosos caminhos", mesmo dos "mais mesquinhos", o "perfeito cristal" ${ }^{4}$ Cabral apresentava em sua poesia, em cristal bruto, diamante ou pedra, uma luta silenciosa como a dor do sertanejo, por uma escrita contra a sentimentalidade, pela utilização da imagem em palavra concreta, avessa aos simbolismos e lirismos do romantismo decadente. Sobre escrever, Mallarmé sentenciou: “[...] não se escreve, luminosamente, sobre campo obscuro, o alfabeto dos astros, só ele, assim se indica, esboçado ou interrompido; o homem prossegue preto sobre branco" (2010, p. 170), e assim prosseguia Cabral, com limites claros e definidos, do preto e do branco, e mesmo que se entremeassem os limites, mantinham cada um, sua dura essência.

Como referência de pensamento filosófico, João Cabral cita o pintor, urbanista e arquiteto francês Le Corbusier, reafirmando sua quase obsessão pelo construtivismo da linguagem, na busca de versos que recuperassem a palavra/objeto, onde a palavra maçã dissesse mais aos sentidos do que a palavra tristeza. Iluminados, toureiro, touro e plaza de toros também deixam ao poeta uma lição de geometria. Despida do seu caráter míticofolclórico, a corrida de toros pode ser analisada com o olhar asséptico do poeta geômetra que encontra nela mais um dos símiles da sua construção poética. Versos que dissessem o abstrato através do concreto.

O poeta pernambucano enredou-se com a arte espanhola e a poesia medieval. A presença do Cantar de Mio Cid, os cantares de gesta e Gonzalo de Berceo ${ }^{5}$, podem ser apreendidos em sua rima toante. Jorge Guillén e Rafael Alberti também estão presentes com a obsessão pela simetria onde a forma ocupa um lugar central. Em sua expressão contemporânea, a Generación del 27 constitui uma das principais vertentes de afinidade do poeta pernambucano, uma reunião em Barcelona de poetas, pintores, músicos, cineastas, cantaores e bailaoras. Entre os poetas estavam Jorge Guillén, Federico García Lorca, Pedro Salinas e Miguel Hernández, todos eles citados nos poemas de João Cabral de Melo Neto.

poética de Mallarmé consiste em suprimir o autor em proveito da escritura". (LÉVY, 2011 apud BARTHES, 1988, pp. 66, 67)

${ }^{3}$ MALLARMÉ, Sthéphane. "Crise de verso". In: Divagações. Tradução e apresentação de Fernando Sheibe. Florianópolis: Editora da UFSC, 2010, p. 164

${ }^{4}$ Referência ao poema "Debruçado sobre os cadernos", de Paul Valéry.

${ }^{5} \mathrm{~A}$ epígrafe "quiero que compongamos io e tu una prosa" do poeta espanhol do Reino de Castela, Gonzalo de Berceo, precede O Rio, poema de Cabral de 1953. A Berceo Cabral consagrará o Catecismo de Berceo, com suas quatro lições de poesia. 
Daí também sua aproximação com as artes pictóricas através da amizade com Joan Ponç, Antoni Tàpies e Joan Miró, quando viveu em Barcelona de 1947 a 50, o que lhe proporcionou a participação no movimento de vanguarda Dau al Set, fundado em 1948. Em 1949 escreve sobre o amigo Joan Miró por encomenda do mesmo, em obra publicada em Barcelona em 1950, pelas Editions de L’Oc. Em seu texto sobre Miró, Cabral define o pintor como "essencialmente marcado pela preocupação de construir" (2003, p. 693). Nestes comentários sobre o pintor catalão podemos distinguir o pensamento criativo do próprio poeta pernambucano, quando fala do "esvaziamento do simbólico" e da "luta contra o instintivo" realizado por Miró. É elucidativa a seguinte passagem:

\begin{abstract}
A Miró, a seu espírito artesanal, quase, haveria de soar estranhamente a estética antiplástica dos surrealistas, que pareciam interessados em criar um tipo de arte superior e independente dos gêneros de arte, pairando independente da realização objetiva de uma obra e, às vezes, capaz de existir apesar de uma obra ${ }^{6}$ (Cabral, 2003, p. 713).
\end{abstract}

Cabral critica nos surrealistas a espontaneidade devida à criação através de automatismo psíquico e desprezo pela forma. E pensando Sevilha, traduz-se o pensamento em versos nos poemas dedicados aos motivos da Espanha, como em "Alguns toureiros", poema de 1954/55, onde o toureiro Manuel Rodrigues, "o mais asceta”, demonstrava aos poetas a maneira de cultivar a flor com controle e contenção da explosão espontânea, instintiva. Sobre o poema, Susana Scramim argumenta que "o poeta diz que vê e que compreende o 'cultivo' de uma 'demonstração', portanto, ele compreende a lição que advém de um culto" (2011, p. 8). Seguem os dois últimos parágrafos e a lição de poesia de Manolete:

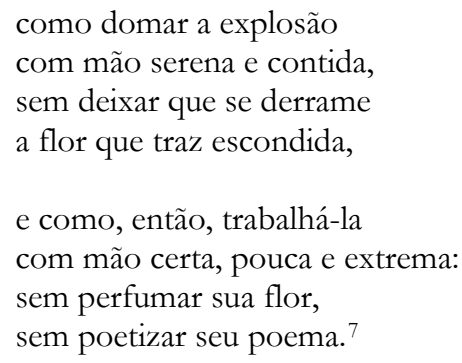

A lição do toureiro é a da contenção elegante perante o perigo, como diria Michel Leiris no Espelho da tauromaquia, de 1968, o "domínio do perigo, tanto para o criador (que, a cada instante deve se arriscar a se perder) quanto para a obra (a cada momento comprometida, constantemente feita e desfeita)" (2001, p. 24).

\footnotetext{
${ }^{6}$ MELO NETO, João Cabral de. "Joan Miró”. In: Obra completa/João Cabral de Melo Neto. Rio de Janeiro: Nova Aguilar, 1994, p. 713.

${ }^{7}$ MELO NETO, João Cabral de. "Paisagem com figuras". In: Obra completa/João Cabral de Melo Neto. Rio de Janeiro: Nova Aguilar, 1994, p. 713.
} 
De Sevilha surge uma poética de face mais feminina, a que percorre a cidade. Surge a mulher espiga, a bailaora. Nas diferenças que se colocam entre Recife e Sevilha nas críticas que se fazem sobre o poeta pernambucano, a que mais traduz a irrelevância dessa diferença, ou comparação, aparece no comentário de Carlos Drummond de Andrade sobre os poetas de Pernambuco, de onde "nos vem a poesia menos nordestina possível". Da poesia de Cabral, Drummond diz ser "isenta de qualquer localismo", sem circunstâncias históricas ou geográficas, intemporal. E acrescenta que "a terra natal fica sendo ponto de partida para uma viagem aos países da geografia interior" ${ }^{\prime 8}$.

No prosaico "Coisas de cabeceira, Sevilha", poema que compõe $A$ educação pela pedra, de 1962/65, uma mesma lição vem da Espanha para compor sua "geografia interior" e se expõe em poesia nas "coisas bem concretas, em suas formas nítidas", como as expressões dos ciganos, "claras e concisas":

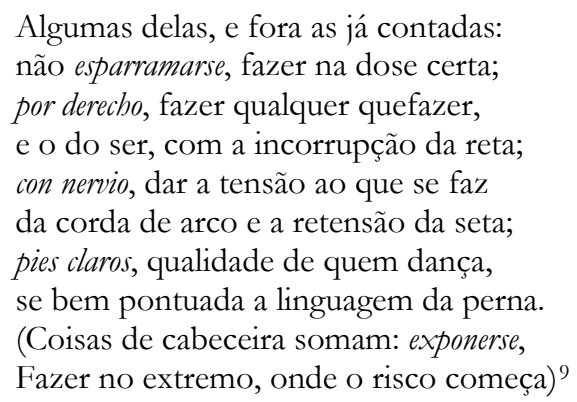

O exponerse refere-se ao risco e ao extremo, do toureiro frente ao touro e do poeta frente à sua construção. Trata-se de uma complexa construção elaborada com a experiência do fora e reelaborada a partir de uma geografia interior de memórias e racionalizações das mesmas. João Cabral conduz sua escrita como um arquiteto ou como um geômetra, como o chamou Haroldo de Campos. No entanto, a geometria de sua linguagem, como já dito, guarda risco e extremos, e quanto maior a paixão e o arrebatamento, também maior o risco. Exponerse é inerente ao flamenco e à corrida de toros. E se há algo de trágico e passional ao extremo no Cante e Baile, Cabral também os incorpora e os habita, embora para muitos críticos, a maioria deles, passe incólume aos excessos. Se há contenção e domínio, o material o exige, e a escolha pelo tema não pode ser ignorada. A insistência em lhe caracterizar por essa economia do excesso talvez explique a leitura por vezes truncada que se fez do poeta.

${ }^{8}$ Conforme artigo de CAVALCANTI, Claudia. "Paisagem cabralina". Cult Revista Brasileira de Literatura. Número 29, dezembro de 1999, p. 31.

${ }^{9}$ MELO NETO, 1994, p. 344. 
$\mathrm{Na}$ elaboração de sua geografia interior e sua experiência do fora, vale lembrar que o Recife também ocupa a cabeceira do poeta, que também nomeou a um de seus poemas "Coisas de cabeceira, Recife", onde as coisas pernambucanas se agrupam na memória, coisas densas que se apresentam nos telhados, nos sobrados, "formando módulos".

Mas é na Sevilha feminina, concha recôndita, que o poeta inventa-se um andaluzismo e apreende "o esqueleto essencial a um poema". Se ambas as cidades ocupam sua cabeceira, é Sevilha que o poeta tem em sua cama.

Tenho Sevilha em minha cama,
eis que Sevilha se fez carne,
eis-me habitando Sevilha
como é impossível habitar-se. ${ }^{10}$

Os ciganos da Triana ou a pobreza de Macarena também correm paralelo ao caminho da morte, como o Severino no caminho do rio Capibaribe, mas é o sevilhano que sustenta o andar desafiante, "o esbelto pisar decidido" das bailadoras e dos toureiros, é o sevilhano que ostenta o cante, é em Sevilha onde o poeta habita a alma extrema, flamenca. $\mathrm{Na}$ usina, no engenho ou na praça de touros, cabem, no entanto, esta mesma alma limítrofe, onde a morte incide na vida, como o preto no branco, indefectível. Conforme o crítico espanhol Nicolás Extremera Tapia,

la más exitosa fuga que realiza el poeta es renunciar a su confrontación con el tiempo ubicándose en un espacio sexuado. Mudar de espacio, entrar en un ámbito sexual, habitarlo de modo que el tiempo ya no sea sentido y se exorcice la presencia de la muerte. ${ }^{11}$

Nesse limiar entre vida e morte, no espaço sexuado e feminino da Andaluzia, inscrevem-se os poemas que tangenciam o poeta com homens e lugares, coisas e linguagens. Falando da tauromaquia e dos construtores de espelhos, Michel Leiris escreve:

\begin{abstract}
Incorporar a morte à vida, torná-la de certa maneira voluptuosa (como o gesto do torero conduzindo suavemente o touro nas dobras de sua capa ou de sua muleta), tal deve ser a atividade desses construtores de espelhos, quero dizer: de todos aqueles que têm por propósito mais urgente agenciar alguns desses fatos que podemos tomar por lugares onde o homem tangencia 0 mundo e a si mesmo $[\ldots]^{12}$
\end{abstract}

\footnotetext{
${ }^{10}$ Primeira estrofe de "Lições de Sevilha". In: Sevilha andando. Obra completa/João Cabral de Melo Neto. Rio de Janeiro: Nova Aguilar, 1994, p. 713.

${ }^{11}$ TAPIA, Nicolás Extremera Tapia. “João Cabral de Melo Neto y la Generación del 27”. Artifara, n. 8, (enero - diciembre 2008), sección Addenda.

${ }^{12}$ LEIRIS, Michel. O espelho da tauromaquia. Tradução de Samuel Titan Jr.. São Paulo: Cosac \& Naify, 2001, p. 75.
} 
$\mathrm{Na}$ mulher sevilhana, a mesma fímbria da morte e a mesma intensidade viva da cidade. Tangenciam-se a mulher e a cidade, numa nervura, na construção de outro espelho de Cabral. No poema "Cidade de nervos", de Sevilha andando, reencontramos a bailadora andaluza de "Estudos para uma bailadora andaluza", de Quaderna, 1956/59. E não só a bailadora e a cidade, mas também sua linguagem, dançam num mesmo ritmo arquitetônico, o ritmo taconeado das siguiriyas. Nos dois poemas citados, as imagens são recorrentes, os "gestos do fogo" da "carne de fogo,/ só nervos, carne toda em carne viva" da bailadora espelham-se na cidade.

\section{CIDADE DE NERVOS}

Qual o segredo de Sevilha?

Saber existir nos extremos

como levando dentro a brasa

que se reacende a qualquer tempo.

Tem a tessitura da carne

na matéria de suas paredes,

boa ao corpo que a acaricia:

que é feminina sua epiderme.

E tem o esqueleto, essencial

a um poema ou um corpo elegante,

sem o qual sempre se deforma

tudo o que é só carne e sangue.

Mas o esqueleto não pode,

ele que é rígido e de gesso,

reacender a brasa que tem dentro:

Sevilha é mais que tudo, nervo. ${ }^{13}$

Luís Costa Lima (1966, p. 362) fala da bailadora, embora ainda nem soubesse da reunião dos poemas que se realizaria em Andando Sevilha, em 1989, com essa mesma ideia da nervura que é do corpo e da escrita, da Espanha que pode ser localizada dentro do Nordeste, da dureza plástica e da resistência ao mítico e às sentimentalizações.

Esse corpo de ardor está mais para o corpo vivo pelas facas que cultiva do que para o corpo que, por sua ardência e sensualidade, carnalmente cativa. Ou seja, o corpo que aqui se cultiva antes se refere a outras imagens do corpo constituídas na obra do poeta, as quais, em comum, apontam para certa ideia de homem, mineral e ossos, de carne transformada em nervos, para dele extrair maior potência ativa de luta, tanto contra a vida Severina, como contra as sentimentalizações.

${ }^{13}$ MELO NETO, João Cabral de. "Cidade de Nervos". In: Sevilha andando. Obra completa/João Cabral de Melo Neto. Rio de Janeiro: Nova Aguilar, 1994, p. 713. 
Essa não concessão de Cabral ao terreno onírico, lírico ou mítico - preservando-se aqui as concessões às imagens surrealistas, algo oníricas, que povoam alguns de seus livros, em especial os primeiros, como Pedra do sono, de 1940/41, e O engenheiro, de 1942/45, é a tão propalada negação a qualquer interferência advinda de inspiração. Sua atitude antilírica lhe renderia algumas antipatias e até a recorrência da crítica ao mesmo tema "contra a poesia dita profunda" ${ }^{14}$.

Apenas como curiosidade e exemplo de uma leitura supostamente sugestionada de João Cabral, podemos citar uma passagem jocosa do texto Contos d'escárnio. Textos grotescos, de 1990, de autoria da escritora, também poeta, Hilda Hilst (1930-2004), que não se furta a um comentário "grotesco" desferido contra João Cabral de Melo Neto na fala do personagem Crasso.

\begin{abstract}
Ele deslizava a lâmina da faca na água da bacia. Lembrou-se de um poeta que adora facas. Que cara chato, pô. Inventaram o cara. Nada de emoções, ele vive repetindo, sou um intelectual, só rigor, ele vive repetindo. Deve esporrar dentro de uma taboa de logaritmo. Ou dentro de um dodecaedro. Ou no quadrado da hipotenusa. Na elipse. Na tangente. Deve dormir num colchão de facas. Deve ter o pau quadrado. Êta macho rigoroso! Chato chato. ${ }^{15}$
\end{abstract}

Não há aqui a intenção de uma análise dessa crítica. O trecho foi colhido de uma obra de ficção, portanto trata-se de uma crítica ficcional, ou melhor, um dos "escrachos" a que se permite a linguagem da escritora paulista. Mas evidentemente deixa transparecer o entendimento da poesia de João Cabral por Hilda Hilst, muito mais afeita à linguagem poética de autores como o alagoano Jorge de Lima, o tcheco Rainer Maria Rilke ou o espanhol da Andaluzia, Federico Garcia Lorca. Com a devida cautela, acrescente-se que não há também o intuito de separá-los em campos distintos, ou como ironizou Mallarmé a respeito de um "desejo inegável de seu tempo", o desejo de separar "como em vista de atribuições diferentes o duplo estado da fala, bruto ou imediato aqui, lá essencial"16.

Marly de Oliveira, sua esposa desde 1986, e a quem Cabral dedicou Andando Sevilha, afirma no prefácio da publicação das Obras completas, pela editora Aguilar, de 1994, tratar-se de "uma poesia dirigida ao intelecto"17, motivada em grande parte pela função de funcionário público associada ao pensar sobre a matéria do poema, o que lhe teria acarretado uma "cisão interna" e sérios prejuízos à saúde.

\footnotetext{
${ }^{14}$ Referência ao poema "Antiode", de Psicologia da composição, de 1946/47.

${ }^{15}$ HILST, Hilda. Contos d'escárnio. Textos grotescos. São Paulo: Siciliano, 1990.

${ }^{16}$ MALLARMÉ, Sthéphane. "Crise de verso". In: Divagações. Tradução e apresentação de Fernando Sheibe. Florianópolis: Editora da UFSC, 2010, p. 164

${ }^{17}$ OLIVEIRA, Marly. “João Cabral de Melo Neto: breve introdução a uma leitura de sua obra”. In: Obra completa/João Cabral de Melo Neto. Rio de Janeiro: Nova Aguilar, 1994, p. 15.
} 
O crítico José Castelo em programa exibido na TV Brasil ${ }^{18}$, em 28 de setembro de 2009, conta que Cabral dizia sofrer de melancolia "como os poetas do séc. XIX". Castelo fala ainda que a suposta frieza que lhe é atribuída escondia um Cabral apaixonado, e a maneira racional e organizada no trato com a escrita dissimulava um "caos em sua cabeça". É conhecida sua dor de cabeça crônica. E a poesia não é sempre a mesma construção indestrutível em pedra. O carvão é o avesso da árvore, é a morte da árvore, assim como ao laranja cítrico do sol adere-se um sol negro.

Nos poemas referentes à Sevilha, Cabral reivindica a presença de um sol ácido, cítrico, laranja, uma claridade que fere a retina, mas também fala de um sol negro, ambos presentes em seu acordar, em seus primeiros passos onde a cada dia inaugura-se um re-ser, acordar e voltar a ser, onde a massa escura é o farol às avessas, sem luz. A melancolia parece advir desse sol, onde o refazer-se é doloroso e inseguro.

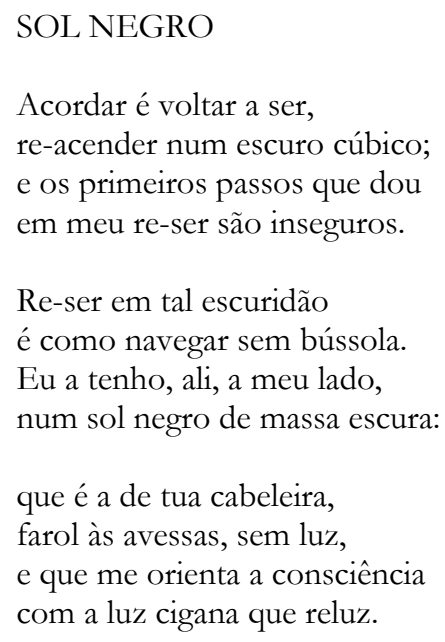

A respeito dessa dor de cabeça e sua fotofobia, cumpre lembrar a homenagem de Cabral ao ácido acetilsalicílico, a aspirina e seu acabamento de cristal, no poema "Num monumento à aspirina" " A aspirina é o sol artificial, que "acende, para secar a aniagem da alma”. Para Kristeva (1989, p. 13), em sua leitura do sol negro da depressão e da melancolia, "não existe imaginação que não seja, aberta ou secretamente, melancólica". O registro desse imaginário, restrito no poeta à imagem escrita, é a poesia, é a linha de fuga representada nos lugares de sua predileção. Do melancólico, Kristeva disse ainda que "com seu interior pesaroso e secreto, é um exilado em potencial, mas também um intelectual capaz de fazer brilhantes construções... abstratas" (1989, p. 64), a se acrescentar aqui, no caso de Cabral, construções concretas a partir das abstrações. O movimento parte do 
interior para o exterior, geografia interna que se inscreve na experiência do fora, ou viceversa, como a cidade de Sevilha, "interna-externa, noitedia” (Cabral, 1994, p. 634).

Sem a pretensão de adentrar a teoria sobre a melancolia elaborada por Freud no início do século XX, até porque a visão clínica da então nascente psicanálise não percorre os sintomas da tradição literária e seu pathos, há que se relacionar a melancolia à perda inconsciente que se elabora em identificação com pessoa, coisa, ideia ou lugar.

É a partir da psicanálise que se estabelece a relação do melancólico com seu objeto perdido, relacionamento este que ocorre num cenário de ambivalência. "Na melancolia, a relação com o objeto não é simples; ela é complicada pelo conflito devido a uma ambivalência". ${ }^{20}$ Extremera Tapia afirma ser a poesia de Cabral "feita de dualidades: vida/morte, mineral/vegetal, Pernambuco/Espanha, abstrato/concreto."21

Além da aspirina, Cabral utilizou-se de um "fluído ambíguo de Sevilha" como o seu álcool ou narcótico por excelência, eleito depois de ter sido curtido nas "várzeas pernambucanas", nos "versos de Appolinaire", como descrito no poema "Meu álcool". Neste poema Cabral intensifica seu objeto em linguagem e clima de Sevilha, onde reside o claro, o limpo e o intenso. Dessa "intensidade que nunca é prolixa" de Sevilha, há um objeto perdido que à distância se dá a ver, na cidade, na mulher, no rio, na terra seca que revela o homem de cultura não domesticada, como o nordestino e o sevilhano. O poeta, o povo andaluz ou o povo nordestino padecem de uma mesma melancolia da terra, escavam a força dionisíaca dos subterrâneos.

Em entrevista concedida a Arnaldo Jabor, João Cabral confessa: "Saio do poema suando, com picareta. Minha obra é motivo de angústia. O sujeito tem de viver no extremo de si mesmo" (Melo Neto, apud Jabor, 2007). Susan Sontag enumera características do melancólico em Walter Benjamin que bem poderiam fornecer um retrato do poeta Cabral. Ambos tiravam muito de sua própria sensibilidade de sua relação fantasmagórica, astuta, sutil com as cidades, ambos projetavam a si mesmos e a seus temperamentos, em todos seus grandes temas e seu temperamento determinava o que elegiam como matéria de escrita. Acima de tudo, compartilham uma devoção compulsiva pelo trabalho. O estilo de trabalho do melancólico é a imersão, a concentração total. ${ }^{22}$

\footnotetext{
${ }^{20}$ Conforme STRACHEY, James. Sigmund Freud. Nota do tradutor inglês - Trauer und Melancolie. Rio de Janeiro: Imago: 1996, p. 261.

${ }^{21}$ Conforme BONVICINO, Régis. O artista confesso. Sibila Poesia e Cultura.

${ }^{22}$ SONTAG, Susan. Bajo el signo de Saturno. Traducción de Juan Utrilla Trejo. Buenos Aires: Debolsillo, 2007.
} 
Transposto à escrita, a identificação de Cabral revela a crise de nervos que é crise de $\operatorname{versos}^{23}$, na linguagem irritada, enervada, em estado crítico, de sua poética, na maneira obsessiva do geômetra que recolhe poemas medievais, canções de gesta, romanceiros e outros cantos populares nordestinos, além da emoção contida e tudo lapida com lâmina e esculpe em pedra.

Considerando a crítica de Marcos Siscar ao Concretismo e seu mérito de "sonhar com o que se poderia fazer além do verso", podemos talvez situar Cabral na esteira deste objetivo. Sua lição de poesia, seu legado à literatura, certamente possibilita este "além do verso", este habitar-se a poesia que enfatiza Siscar como herança de uma crise.

[...] o Concretismo tornou mais sensível o caráter contraditório e dramático da habitação da própria linguagem, seu elemento problemático e urgente, sua seiva histórica ("inercial”) específica, seus lugares de saturação, o dilema em que consiste a ideia de sua superação. ${ }^{24}$

A superação se fez concreta na exata medida do esquadro que disfarça o eclipse de um sol negro, ou na superfície extrema e exposta da laranja cortada ao meio pela faca afiada de uma linguagem. João Cabral de Melo Neto guardou a lição de poesia do toureiro "Manolete, o mais asceta", uma poesia trabalhada "com mão certa, pouca e extrema:/ sem perfumar sua flor,/ sem poetizar seu poema” (Cabral, 1994, p. 158). No entanto, na superação, a sempre inerente possibilidade extrema, o risco de se perder.

\section{Referências bibliográficas}

BACHELARD, Gaston. A psicanálise do fogo. Tradução de Paulo Neves. 2 Ed.. São Paulo: Martins Fontes, 1999.

BLANCHOT, Maurice. O espaço literário. Tradução de Álvaro Cabral. Rio de Janeiro: Rocco, 2011.

BONVICINO, Régis. "O artista confesso". Sibila Poesia e Cultura. Disponível em

http://www.sibila.com.br/index.php/critica/128-o-artista-confesso. Acesso em 18 de janeiro de 2012.

"Miró e Cabral: linhas cruzadas". Sibila Poesia e Cultura. Disponível em http://www.sibila.com.br/index.php/critica/109-linhas-cruzadas Acesso em 18 de janeiro de 2012.

CAMPOS, Augusto de. "Da antiode à antilira". In: Poesia, antipoesia, antropologia. São Paulo: Cortez e Moraes, 1978.

\footnotetext{
23"Crise de vers" é um dos textos de Divagações, de Mallarmé. Marcos Siscar faz o paralelo com o termo crise de nerfs, quando relaciona a crise de verso com uma "irritação do verso", ao se deparar não somente com seu contexto histórico, mas acima de tudo, com a bifurcação da métrica da tradição versificada, a poesia verbal, e a vanguarda que propõe uma suposta primazia da forma, a poesia visual. (2010, p. 107)

${ }^{24}$ SISCAR, Marcos. "Poetas a beira de uma crise de versos". In: Poesia e crise: ensaios sobre a "crise da poesia" como topos da modernidade. Campinas: Editora da Unicamp, 2010, p 106.
} 
CAMPOS, Haroldo. Metalinguagem \& outras metas. São Paulo: Perspectiva, 1992.

CAVALCANTI, Claudia. "Paisagem cabralina". Cult Revista Brasileira de Literatura. Número 29, dezembro de 1999, p. 31.

FERRAZ, Eucanaã. "Belo, Bula". In: A educação pela pedra e outros poemas / João Cabral de Melo Neto. Rio de Janeiro: Objetiva, 2008.

JABOR, Arnaldo. "João Cabral nos mostra o Brasil em negativo". Gažta Digital. 28 de agosto de 2007.2 Disponível em: http://www.gazetadigital.com.br/conteudo/show/secao/10/materia/152930. Acesso em 22 de janeiro de 2012.

LEIRIS, Michel. O espelho da tauromaquia. Tradução de Samuel Titan Jr.. São Paulo: Cosac \& Naify, 2001.

LEVY, Tatiana Salem. A experiência do fora: Blanchot, Foucault e Deleuze. Rio de Janeiro, 2011.

LIMA, Luis Costa. "A traição consequente ou a poesia de Cabral". In: Lira e antilira: Mário, Drummond, Cabral. Civilização Brasileira.

MALLARMÉ, Sthéphane. "Crise de verso". In: Divagações. Tradução e apresentação de Fernando Sheibe. Florianópolis: Editora da UFSC, 2010.

MELO NETO, João Cabral de. Obra completa/João Cabral de Melo Neto. Rio de Janeiro: Nova Aguilar, 1994.

- A educação pela pedra e outros poemas. Rio de Janeiro: Objetiva, 2008.

NIETZSCHE, Friedrich Wilhelm. Humano, demasiado bumano. Tradução de Paulo César de Souza. São Paulo: Companhia das Letras, 2005.

PEDRA, Nylcéa Thereza de Siqueira. Um João caminha pela Espanha. (Doutorado em Letras - Estudos Literários). Curitiba, Universidade Federal do Paraná, 2010.

SCRAMIM, Susana. "Sobre a possibilidade de dizer 'eu". Anais do XII Congresso Internacional da ABRALIC. Centro, Centros - Ética, Estética. De 18 a 22 de julho de 2011, UFPR: Curitiba. Disponível em http://www.abralic.org.br/anais/cong2011/AnaisOnline/resumos/TC0039-1.pdf. Acesso em 16 de janeiro de 2012.

SISCAR, Marcos. "Poetas a beira de uma crise de versos". In: Poesia e crise: ensaios sobre a "crise da poesia" como topos da modernidade. Campinas: Editora da Unicamp, 2010, p 106.

SONTAG, Susan. Bajo el signo de Saturno. Traducción de Juan Utrilla Trejo. Buenos Aires: Debolsillo, 2007.

TAPIA, Nicolás Extremera Tapia. "João Cabral de Melo Neto y la Generación del 27”. Artifara, n. 8, (enero - diciembre 2008), sección Addenda. Disponível em: http://www.artifara.unito.it/Nuova\%20serie/Artifara-n--

Addenda $/$ default.aspx?Login $=$ true\&oid $=98 \&$ oalias $=$ 